\title{
AL COMPÁS DE LA TONADA ESTATAL: CONFLICTO AGRARIO EN SARAPIQUÍ, 1980-2009
}

\section{DANCING TO THE STATE'S BEAT: AGRARIAN CONFLICT IN SARAPIQUÍ, 1980-2009}

\author{
María José Guillén Arayal
}

Fecha de aceptación: 14 de noviembre de 2017 - Fecha de aceptación: 26 de febrero de 2018

\begin{abstract}
Resumen
Este artículo estudia dos episodios de ocupaciones de tierras en la zona de enclave bananero de Sarapiquí, durante el periodo que va de 1980 al 2009 para conocer el papel que cumple el estado en los procesos políticos de conflicto agrario. En el análisis de las narrativas campesinas -en torno a las tomas de tierra, a las negociaciones públicas, las acciones colectivas y las disposiciones discursivas y organizativas- se problematiza las nociones de "ausencia" y/o "abandono" estatal, para llegar a la conclusión de que el estado puede estar institucionalmente ausente cuando se le piensa desde el ideal benefactor, pero presente selectivamente en procesos de judicialización, criminalización y represión; asimismo, se demuestra como el estado está donde menos se le busca: en las prácticas organizativas campesinas y su anhelo cotidiano de reconocimiento legal. El ajuste estructural promovió la contracción estatal, sin embargo, se concluye que ésta no fue absoluta, ocurrió en los ámbitos redistributivos más no así en los represivos.
\end{abstract}

Palabras clave: clase campesina; estado; estructura agraria; tenencia de la tierra; enclave bananero ${ }^{2}$.

\begin{abstract}
Along this paper I study two cases of land occupations at the banana enclave zone of Sarapiqui from 1980 to 2009, in order to know the state's role in political processes of agrarian conflict. The analysis of the peasant's narratives -on land occupation, public negotiation, collective action, discursive and organizational dispositions- problematizes the notions of state's "absence" and/or "abandonment", leading to the conclusion that the state can be absent in its institutional forms when it is understood within the welfare ideal, but selectively present when it comes to judicialization, criminalization and repression; also, is shown that state is found where is least looked for: in peasant's organizational practices and daily desire for legal recognition. Structural adjustment promoted state's institutional reduction, however, reduction wasn't absolute, and this study concludes that such withdrawal occurred in redistributive policies, not in the repressive ones.
\end{abstract}

Key Words: peasantry; state; agrarian structure; land tenure; banana enclave.

\section{Introducción}

La historia de Sarapiquí está marcada por el conflicto agrario, las plantaciones bananeras que empezaron a crecer desde la década de 1960 toparon también con la organización social de familias obreras que deseaban un pedazo de tierra para trabajarla como campesinos. Esta tensión tan viva en los

1 Escuela de Ciencias Políticas, Universidad de Costa Rica, maria.guillen.araya@gmail.com

2 "Enclave bananero" es una palabra clave que no se encuentra registrada en el Tesauro de la UNESCO. 
años ochenta no terminó con el golpe que sufrió la pequeña producción agrícola durante la aplicación de los planes de ajuste estructural, el caso de la ocupación de tierras conocidas como El Bambuzal durante la primera década del siglo XXI da cuenta de esto.

Sarapiquí interesa porque, contrario a las tesis de proletarización de la población rural por el desarrollo del capitalismo (Lenin, 1972; Kautsky, 2015), las dinámicas sociales y políticas del conflicto en este espacio del campo costarricense "incumplen" la condena de desaparición del campesinado. Contra todo pronóstico se fundaron asentamientos campesinos como San Bernardino; pero, la agencia de las organizaciones campesinas está estructurada según las formas de entender al estado ${ }^{3}$. Desde las ciencias sociales nos hemos abocado a dar al estado por sentado, objetivándolo, exteriorizándolo, fetichizándolo (Abrams, 1988; Mitchell, 1991), sin preguntarnos por su formación en las prácticas sociales (Roseberry, 2007). Justamente esa es la pregunta que motiva este artículo.

Metodológicamente la investigación se basó en los planteamientos del estudio de caso extendido (Gluckman, 1968) de manera que al contener distintos episodios en un periodo de tiempo más o menos extenso (1980-2009), se pueden ubicar cambios y continuidades, tendencias y tensiones. Esto permite una comparación desde una visión procesual, pues no contrapone desenlaces distintos y separados para identificar cambios aisladamente. En cambio, trata de poner los ojos en el proceso para entender las transformaciones de un mismo "objeto" a partir de dos o más estados de desarrollo diferenciado (Ollman, 2003), en este caso, la relación del estado (como instituciones, como ideas, como estructura aparente) con organizaciones campesinas que han recuperado tierras. La selección del marco temporal y territorial, se expone en los apartados siguientes.

El trabajo de campo de la investigación (tesis de Licenciatura en Ciencias Políticas) consistió en un par de visitas de carácter exploratorio entre setiembre y noviembre del 2013 a San Bernardino y Finca 10 (donde se ubicaba buena parte del terreno de El Bambuzal), y nueve visitas durante el 2014 a San Bernardino, Finca 6 y Finca 10 de Río Frío de Sarapiquí. En las giras se realizó observación participante y no participante en eventos comunitarios, entrevistas de historia oral con personas campesinas y vecinas de estos pueblos, en total se trabajó con 10 informantes campesinos. Asimismo, la recopilación de la información se dio a través del análisis documental de investigaciones, actas institucionales, cronologías del conflicto, afiches, videos, y noticias de periódico (todos los números de La Nación para 1985, y de distintos periódicos para el periodo 2004-2009 según criterios de búsqueda).

El artículo contiene un apartado de la configuración histórica (temporal), otro sobre el territorio, para finalmente presentar un análisis de los dos episodios de conflictividad agraria y las conclusiones.

\section{Configuración histórica de la conflictividad agraria en Sarapiquí}

Si bien las expresiones del conflicto en Sarapiquí (concentración de la tierra, explotación laboral, expulsión de mano de obra, ocupaciones de tierra, represión y complicidad de las instituciones del estado) son constantes durante el periodo que abarca ambos episodios, se establece la división temporal a partir de los siguientes criterios, los que a la vez permiten enmarcar las relaciones con el estado durante las ocupaciones de tierra, haciendo el vínculo entre las temporalidades globales, nacionales y locales, aplicables a la realidad estudiada:

a. La aplicación de los planes de ajuste estructural en Costa Rica ocurrió desde el gobierno de Luis Alberto Monge (1982-1986) hasta el de José María Figueres (1994-1998), en la etapa siguiente consolidó de este nuevo modelo surgido en los ochenta;

3 Para desfetichizar al estado (Abrams, 1988), hay que empezar a comprenderlo ya no como superior, vertical y separado de las prácticas cotidianas, ya no como Estado con existencia independiente y nombre propio, sino como estado, en minúscula. 
b. En los ochenta, el desestímulo a los subsidios para el sector de pequeños productores, la reconversión productiva agroexportadora, la eliminación del control de precios, la reducción de los presupuestos dirigidos a la compra y titulación de tierras, fueron factores que vinieron acompañados, a partir de los noventa, de un decrecimiento en la cantidad de ocupaciones de tierra y de sus posibilidades de éxito en cuanto a acceso, así como de un debilitamiento de los movimientos campesinos y de los sindicatos rurales ${ }^{4} ; \mathrm{y}$,

c. Las compañías transnacionales que dominaban la producción y comercialización del banano en Costa Rica (Dole y Chiquita) experimentaron un periodo económicamente crítico la mayor parte de los ochenta, pero su recuperación inició en los noventa y se consolidó en los años $2000^{5}$.

Los desenlaces del conflicto resultaron distintos. San Bernardino logra mantenerse en el tiempo, las parcelas fueron tituladas y se llega a constituir una comunidad campesina. El Bambuzal no logró el acceso a la tierra, los campesinos y campesinas fueron expulsados y migraron hacia otras zonas del país, la comunidad fue solo un proyecto imaginado.

\section{Territorios en disputa: el paisaje agrario de Sarapiquí}

La historiografía del estado en Costa Rica se ha escrito con las letras en el Valle Central, la historia del agro suele ser la del café de las tierras altas de San José, Heredia y Cartago, la historia de nuestro Caribe suele ser la del ferrocarril que lo conectó con la capital, la de la estabilidad democrática es la de las elecciones en las ciudades, la de la robusta institucionalidad es la del centralismo político, y así sucesivamente. Cuando vemos que el espejo siempre nos da la misma imagen, tal vez sea necesario ponerlo al revés, o quebrarlo, y es por eso que en este análisis se corre el foco, territorialmente hacia Sarapiquí como periferia, y socialmente hacia el campesinado como clase social subordinada.

Sarapiquí fue el segundo escenario de la expansión bananera en Costa Rica en los años sesenta, luego de la ruptura del monopolio de la United Fruit Company (UFCo). El cantón era considerado como una zona (aparentemente) vacía, por ser uno de los últimos remanentes de la frontera agrícola. Es la Standard Fruit Company (SFC), hoy Dole la que llega a implantar el monocultivo bananero en la zona. La compañía producía fruta bajo un modelo mixto, de integración y desintegración de la producción, es decir, la compañía todavía poseía una importante cantidad de terrenos en Sarapiquí, por lo que la lógica de enclave continuó funcionando en la zona. En relación con el uso de la tierra, entenderé al enclave como un territorio dinámico, ya que:

debido a los vaivenes del mercado internacional y a los procesos de atracción, captura y expulsión total o parcial de la mano de obra -pues [sic] genera procesos de resistencia que devienen en cambios del manejo productivo (como fue el paso a la des-integración vertical) y en cambios en el paisaje agrícola donde los abandonos y reservas ${ }^{6}$ de dominio de la empresa bananera son constantes focos de conflicto agrario pues son tierras que representan las opciones de subsistencia y trabajo digno que el empleo bananero no pudo garantizar (Guillén, 2015, p.71).

4 Respecto de la aplicación de los planes de ajuste estructural, ver Edelman, M. (2005). Campesinos contra la globalización. Movimientos sociales rurales en Costa Rica. San José: Editorial de la Universidad de Costa Rica. Sobre el descenso en la cantidad de organizaciones rurales y su (des) movilización durante los años noventa, el Capítulo 5 de este libro es especialmente valioso.

5 Esto fue constatado a partir de la revisión de todos los números del periódico La Nación para 1985.

6 Las compañías bananeras poseían mucha más tierra de la que utilizaban, un pequeño porcentaje eran tierras en uso para cultivo o infraestructura, pero el mayor porcentaje estaba por constituido por abandonos, es decir, terrenos cuyos suelos ya habían sido agotados por el cultivo del banano o que estaban enfermos (comúnmente con el mal de Panamá) y que se habían dejado de utilizar, y por reservas, tierras -usualmente bosques- destinadas a siembras futuras una vez se agotaran los suelos que se encontraban en explotación. 
Además de la relación entre la captura y expulsión de mano de obra (ya fuera por sobreoferta de la misma o por su carácter flexibilizado) y la disponibilidad de terrenos en abandono, la toma de tierras vinculadas al enclave también tuvo como motivo las experiencias exitosas de otros ocupantes que lograron obtener titulaciones (Román \& Peraza, 1990). Durante la década de los setenta y ochenta, Sarapiquí fue uno de los principales focos de conflictividad agraria en el país, ya que de 1963 a 1979, en toda Heredia se denunciaron al Instituto de Desarrollo Agrario 92 casos de invasiones de tierra, de los cuales 88 se dieron en Sarapiquí; de 1980 a 1985, se declararon 44 denuncias, siendo 40 correspondientes a Sarapiquí (Cartín \& Román, 1991). A continuación, se analizarán dos casos de conflicto agrario en este cantón.

\section{Episodio I: San Bernardino, estructuras que aparentan existir}

Luego de la instalación de la SFC en Sarapiquí a finales de los años sesenta, el requerimiento de mano de obra causó varias olas de migración hacia la zona de personas con la esperanza de obtener un empleo remunerado. Sarapiquí se convirtió en 1973 el cantón con mayor saldo migratorio positivo del país (Román \& Peraza, 1990). Sin embargo, al estabilizarse la demanda de mano de obra por parte de la compañía, al mismo tiempo que convergen el desempleo y explotación laboral con disponibilidad de tierras en abandono se crean las condiciones para un escenario de potencial conflicto agrario. Tal es el caso de San Bernardino.

El 3 de mayo de 1982 se da la primera entrada de campesinos y campesinas a las tierras que actualmente se conocen como el pueblo de San Bernardino. El paisaje con el que se encontraron era el de terrenos donde existieron árboles maderables de cedro y laurel, que habían sido deforestados y abandonados. Según varias de las personas entrevistadas, no se trataba ni siquiera de fincas, pues las tierras no estaban medidas, cercadas o consideradas para las actividades productivas, oficinas u otra cosa; según sus averiguaciones legales no se encontraban tituladas, aunque se decía popularmente que la bananera era propietaria. (Anónimo, setiembre 16, 2014).

Las tierras no habían pasado por los mecanismos de estandarización que las hiciera legibles al estado (Scott, 1998): la privatización de la propiedad, el pago de impuestos, cercado, medición, registro. Sin embargo, al saber de la ocupación, la compañía movilizó sus esfuerzos para volver legible a los ojos del estado los terrenos, para convertir a la tierra en propiedad. Las y los campesinos recuerdan cuando, la SFC envió un helicóptero a medir las tierras, y recalcan como quedaron mapeados dentro de los planos de la bananera. Esta primera forma de visibilidad ante la autoridad (representada por la bananera dado su papel preponderante en el cantón), era solamente marginal, podían ser borrados del mapa o del catastro, lo que les reafirmaba su carácter de incontados (Ranciére, 2010).

Fueron incontados porque el conflicto de San Bernardino no solo fue obviado por las instituciones públicas y sus autoridades, sino también porque sus formas de habitar y usar el territorio no entraban dentro de las formas captables o legibles por el ojo de las instituciones del estado. Al no tener existencia registral, no había traducción oficial que reconociera su posesión de la tierra como algo legal, este estatus se convirtió en una de las primeras razones de la indiferencia por parte de las instituciones estatales, hecho que fue transformándose a lo largo del conflicto, cuando las y los campesinos organizados decidieron usar distintas estrategias de visibilización, denuncia y demanda.

Aunque el fin último de la ocupación es el aseguramiento de su modo de vida, la legalidad también se vuelve una aspiración. A la necesidad material del terreno, se le amarró la del reconocimiento simbólico de la tenencia. La tierra no es lo mismo que el título, y aunque las familias campesinas consideren que poseen la tierra porque la trabajan, saben también que sin título no hay reconocimiento formal de tal hecho frente al estado, es decir, se traducen hechos y vivencias en una clave de lectura posible al estado. En esta situación como en otras, la metáfora aclamada en Seeing like a State toma sentido: "the categories used by the state agents are not merely means to make their environment legible; they are an authoritative tune to which most of the population must dance" [las categorías utilizadas por los 
agentes del estado no son solo medios para hacer su ambiente legible; son una tonada autoritaria con la que la mayoría de la población debe bailar] (Scott, 1998, p. 83).

Esta aspiración secundaria, derivada de la imposición de la tonada estatal, determina no solo la forma en que se expresa la lucha, sino también su estrategia. Los regímenes de dominación afectan las resistencias, principalmente a través de "formas e instituciones reguladoras y coercitivas del Estado, las cuales definen y crean ciertas clases de sujetos e identidades" (Roseberry, 2007, p. 122).

Dichas identidades y sujetos, no solo reciben de manera impositiva unas formas del decir o del hacer meramente estatales, pues la dominación también tiene un soporte cultural en el que toma forma. Así, en un primer momento, la organización para obtener la tierra fue colectiva, y la que vino después, para hacerse del título, fue individual. Para el aseguramiento del control sobre los terrenos se requirió la participación de la mayor cantidad de personas, por ejemplo, eliminando bosque, construyendo las viviendas temporales o "champas", sembrando, y también poniendo el cuerpo ante la presencia policial o las amenazas de represión: bloqueando una entrada o corriendo la voz de alerta. Luego de tomada la tierra, se hizo un reparto individualizado (por familia o cabeza de familia) de parcelas, la lucha empezó a perder su carácter grupal para ir tomando la forma de una tarea individual: conseguir la titulación de la parcela.

El grupo campesino quería revertir su primera forma de su visibilización, su captura simbólica por el ojo de águila de la SFC que los veía desde un helicóptero. Para ello efectuaron varias acciones colectivas. A un año de iniciada la ocupación, en 1985 la movilización llamada "Marcha al IDA", una multitudinaria actividad en la que participaron unas 400 personas de todo Sarapiquí, quienes se movilizaron a San José para manifestarse públicamente. Las diferentes ocupaciones de tierra del cantón estaban organizadas con el apoyo de la UTCAIS (Unión de Trabajadores y Campesinos Agroindustriales de Sarapiquí) para obtener la legalización de su estatus sobre las tierras.

De acuerdo con el Señor S, las demás tomas de tierra lograron la atención del Instituto de Desarrollo Agrario (IDA), pero a San Bernardino le respondieron que su caso dependía de la bananera, porque esas eran tierras declaradas como "inhabitables", por lo que no obtuvieron el apoyo institucional que reclamaban. El Señor S manifestaba:

Por ahí del 85-86 hicimos la que se llamó 'Marcha del IDA' (...) En el IDA el guarda no nos quería dejar pasar, la marcha era pacífica, pero le tiramos piedras. Igual hicimos luego en la Asamblea Legislativa. En el IDA nos dejaron entrar porque nos le fuimos todos encima y todos los sectores que estábamos batallando entramos. El IDA no nos daba pelota, y nos dijeron que teníamos que pelear con la Standard (Anónimo, setiembre 16, 2014).

En los relatos campesinos que fueron recuperados durante el trabajo de campo, era común este tipo de narrativas que resaltaban la falta de atención de las instituciones. Isabel Román y Damaris Peraza (1990) afirman que esta marcha de mayo de 1985, fue organizada por la Coordinadora Agraria Precarista de Sarapiquí, y que mantuvieron una huelga de hambre tres meses para presionar al gobierno de Luis Alberto Monge para que resolviera los casos de las once fincas invadidas en dicho cantón. En términos territoriales, el desplazamiento de un grupo de campesinos hacia San José, para apelar a las autoridades de gobierno, refuerza la idea del estado como núcleo que despliega centrífugamente sobre el territorio las decisiones y el poder, lo que su distribución institucional valle-centralizada reproduce (León, 2008). Dicha idea determinó el tipo de estrategias utilizadas por la organización, y se vio enfrentada empíricamente con sus propios efectos, pues estas acciones no llamaron la atención más que temporalmente y no variaron la dinámica existente en Sarapiquí. Lo que importa entonces no es si el estado es realmente una estructura centralizada, sino cómo este imaginario impregna las estrategias y acciones políticas, por ello: "it should be examined not as an actual structure, but as the powerful, metaphysical, effect of practices that make such structures appear to exist” [deberíamos analizar al estado no como una estructura, sino como los efectos poderosos y metafísicos de ciertas prácticas que hacen que esa estructura aparente existir] (Mitchell, 1991, p.94). 
El estado, como máscara que oculta a la práctica política (Abrams, 1988) no tenía que estar "presente" con sus oficinas, sus policías o sus trabajadores sociales para actuar; su lenguaje y sus prácticas eran encarnados por aquellos mismos que en principio se pensaban sus antagonistas. Aquella falta de atención de las instituciones no minó el hecho de que los campesinos hablaran, actuaran y tomaran decisiones con criterios institucionales, en sus prácticas cotidianas de organización: llevaron actas, establecieron comités de negociación, se desplazaron hacia los edificios de las instituciones, enfocaron sus objetivos en términos legalistas e individuales; en estas operaciones el título de propiedad se volvió sinónimo de tierra, una abstracción máxima que convierte al trabajo, las emociones y la organización en un documento legal. Los lenguajes de expresión del conflicto en los grupos subordinados quedaron subsumidos a aquellos lenguajes que pudieran ser entendidos en aquella estructura aparente, entonces, "en la medida en que un orden dominante establece tales procedimientos como legítimos, en la medida en que establece no el consenso sino las formas prescritas para expresar tanto aceptación como descontento, ha establecido un marco discursivo común" (Roseberry, 2007, 131).

La realidad que terminó revelándose para el movimiento era que hacia quien había que dirigirse estaba cerca de casa y no en San José. Esto negaba en parte la idea sobre la omnipresencia del estado, pues se empezaba a difuminar su supuesta fuerza, apelada a través de la demanda social de su intervención en el conflicto. El Señor N cuenta que la empresa, para conocer lo que perdía o mantenía, envió evaluadores de suelos a tomar muestras con el objetivo de observar qué tan cultivables eran, dependiendo de la calidad ponía un precio a los títulos que tenían que pagar los campesinos. Como en el conflicto no intervino el IDA, cada unidad familiar tenía que negociar con la Standard.

Bajo una lógica de acumulación, la empresa bananera que pasaba por una situación económica crítica, aprovechaba la ocupación campesina. Por un lado, el contingente de ocupantes -muchos de ellos ex-obreros bananeros- se constituían como un ejército de reserva de mano de obra, por el otro, la venta de los títulos constituía una fuente de ingreso. Hacer rentables los abandonos fue una estrategia ante la crisis financiera de la SFC en los primeros años de la década de los ochenta. La ausencia de institucionalidad estatal dio paso a que la lógica de enclave extendiera sus brazos para asumir labores institucionales de tipo técnico, como la medición de las parcelas, la evaluación de la calidad de los suelos, la generación y venta de títulos, como también labores institucionales de tipo represivo con la presencia de guardas privados y las amenazas de desalojo.

La racionalidad burocrática que por un saber técnico limita la discusión política (Román, 1994), provoca por parte de la institucionalidad, un abandono e indiferencia hacia un conflicto largo y complejo. Bajo la excusa de la inhabitabilidad de los terrenos, se desprotege a los campesinos que terminan en un enfrentamiento asimétrico frente a una transnacional del monocultivo. No hay presencia estatal en el campo directo de intervención, mas no es así el campo más simbólico pero con efectos concretos de dominación, la dinámica política organizativa estaba regida por las formas hegemónicas en que el estado mismo funciona, tanto al influir en la autonomía organizativa de los grupos campesinos, como por imponer un estado de necesidad y dependencia en el que dichas formas son requeridas para obtener lo que se quiere (hay que pagar un título y hay que conocer de la tramitología). Esta lucha fue exitosa en el tanto que la tierra se obtiene y se distribuye a las y los campesinos, pagando el precio de la cooptación organizativa y de condiciones estructurales que hacían difícil el mantenimiento de la parcela y los cultivos en ella.

\section{Episodio II: El Bambuzal, presencias estatales represivas y lenguajes de contienda}

El Bambuzal, Bambusal o Barbusal no existe en los mapas. Es un nombre que suena en los relatos orales campesinos de Sarapiquí o escrito en los archivos de instituciones como el Instituto de Desarrollo Agrario (IDA) y la Defensoría de los Habitantes después de las palabras "conocido como". Es el nombre de una historia fallida de ocupación campesina que fue borrada de los anales del estado y de las fincas que hoy se constituyen como propiedad de la Standard Fruit Company. 
Como antecedente de este conflicto, está el peso de todas las ocupaciones de tierra ocurridas en Sarapiquí en las décadas anteriores, así como las reformas institucionales en materia de distribución de la tierra y reorientación productiva. En 1993 se establece el Plan Nacional de Reforma del Sector Agropecuario que modificaba el rango de acción del IDA, y después del cual se presenta una disminución en la cantidad de compras de fincas que hace el IDA. Del total de las 89 fincas compradas en el cantón de Sarapiquí desde la fundación de la institución en 1963 hasta noviembre del 2014, 67 fincas fueron compradas antes de 1993, y 19 fincas después, 3 fincas de las adquiridas no tienen fecha de compra (INDER, 2014). En esos 30 años del primer periodo, en ese cantón el IDA adquirió 2,2 fincas por año, mientras que en los 21 años siguientes el promedio de compras anual se reduce a menos de la mitad con 0,9 fincas.

La SFC se había recuperado de la crisis económica de los ochenta, y contrario a sus amenazas de abandono permaneció en Río Frío y en el Valle de la Estrella, como una empresa recuperada y renovada, con una presencia predominante en el territorio, mientras continuaba con el sistema combinado de integración (una limitada cantidad de fincas donde era productora directa) y desintegración vertical (compra a empresas independientes de banano, pero con control del procesamiento y comercialización). Durante los años noventa el área cultivada de banano aumentó en todo el cantón, pasando de 2.700 hectáreas a 1.851 en 1985 y de 1.727 hectáreas en 1991 a 6.142 hectáreas en 1997; expansión que corresponde mayoritariamente a la ampliación de fincas de empresas ya instaladas -como la SFC-y en menor medida a la llegada de nuevas empresas (Rodríguez, 1998). Dole (nombre comercial de la casa de la cual es subsidiaria la SFC) lograba expandir su presencia en las tierras de la región Huetar Norte, también con un cultivo estrella de la reconversión productiva: la piña.

Las olas de despidos comunes en el funcionamiento del enclave bananero por las formas estacionales del trabajo, se volvieron críticas para el caso de Río Frío cuando al inicio de la década de los años 2000 la mayoría de los despidos injustificados fueron de trabajadores afectados por el nemagón ${ }^{7}$, sin que mediara ningún tipo de indemnización. Esta fue una de las justificaciones que el grupo de trabajadores bananeros utilizó para ejercer presión moral hacia la SFC, y ésta resarciera el daño donándoles o vendiéndole al estado la finca El Bambuzal (DHR, 2001). Entre 1999 y el año 2001 es que un grupo de unos 300 campesinos y campesinas toma posesión de cerca de 900 hectáreas de terreno en Río Frío de Sarapiquí, pero es hasta octubre del 2004 que la SFC presenta ante juzgados prueba documental del carácter registral y su titularidad sobre la finca. De acuerdo con el abogado a cargo de la causa campesina, los terrenos del Bambuzal eran baldíos nacionales, en el momento en que se instala la SFC en Río Frío fueron anexados a su finca madre "corriendo la cerca" (Monestel, 2005, p.13).

Este caso inicia con la averiguación de las cuestiones jurídicas, y una de las primeras necesidades de la organización campesina es buscar el acompañamiento de un abogado en el proceso, pues las denuncias de la SFC fueron realizadas en sede judicial. Esto es particular porque se relega a un segundo plano la institucionalidad especializada en el tema agrario, siendo la sede judicial el principal canal y por ende el principal conjunto de reglas de negociación, lenguaje de contienda y formas de acción política.

En 1999 el IDA inicia una investigación para la compra de terrenos que puedan beneficiar a las familias que cumplan con los requisitos institucionales, quienes califican aceptan iniciar el trámite para la compra de unas fincas en Pococí, provincia de Limón. La Asociación Nacional de Campesinos de

7 El nemagón es el nombre comercial del compuesto llamado DBCP: 1,2-dibromo-3-cloropropano (DBCP) "aunque se había sintetizado anteriormente; en la década de los cincuenta, los laboratorios de Shell Oil Company y Dow Chemical Company, observaron la efectividad del DBCP para combatir a los nemátodos; de la misma forma que también detectaron la efectividad para causar diferentes patologías en animales de laboratorio. Sin embargo, el silencio se volvió sepulcral y algunas pruebas se omitieron y obviaron. En 1955, Shell inició su producción y en 1964 fue registrado el producto, tras unos controles médicos a los trabajadores en la planta de Denver. No obstante, nadie advirtió al médico que analizara el blanco más vulnerable para el DBCP: el aparato reproductor masculino" (Boix, 2005). 
Sarapiquí (ANCS) sufre entonces una escisión entre quienes aceptan la propuesta del IDA y quienes deciden quedarse a defender la ocupación de las fincas de El Bambuzal, estos últimos pasaron a llamarse Asociación de Ocupantes El Bambuzal (AOB). Además de la convicción de defender los terrenos que se habían ocupado, defendido y cultivado, la división del grupo tuvo que ver además con dinámicas de poder internas dentro de la organización, como el ejercicio vertical y autoritario de algunos líderes.

Para las familias que aceptaron ser reubicados en Pococí, el IDA conformó el asentamiento "El Maná" de la compra de tres fincas adyacentes con distintos dueños. Para la compra de los terrenos la institución se encargó de velar por el cumplimiento de los requisitos de las familias "beneficiarias", así como de hacer los estudios socioeconómicos y técnicos registrales, de calidad de los suelos, y de compra. Los tres expedientes de compra de las fincas coincidían en que se debía sembrar raíces y tubérculos para el mercado: ñame, yuca plátano y maíz para elote (del cual el mercado no estaba asegurado, y las y los campesinos deberían buscar los contactos para lograr su colocación), sin embargo, la mayor parte del área de las fincas no era apta para cultivar por problemas de textura, profundidad efectiva y drenaje (INDER, 1999-2003).

Los datos de los estudios sobre las propiedades agrícolas de los terrenos revelaron su falta de viabilidad, lo que demostraba que la "racionalidad burocrática" (Román 1994, 61) basada en el saber tecnocrático estaba más presente como discurso que como soluciones institucionales concretas. Desde las instituciones se busca alivianar de manera temporal un conflicto a costa de las situaciones que tienen que pasar los supuestos "beneficiarios" para poder producir, así como a costa del constreñimiento de lo que se consideran tierras para la redistribución, categoría dentro de la que no cabían las tierras de El Bambuzal, pues la falta de voluntad de la compañía para negociar una venta determinó la imposibilidad de compra por el IDA, que no consideró la expropiación.

Esa fue la respuesta estatal para el grupo desplazado, para quienes se quedaron como AOB la relación con la institucionalidad se dio en dos niveles: uno, superficial e intermitente con instituciones encargadas de velar por garantías y derechos (Defensoría de los Habitantes de la República, Patronato Nacional de la Infancia); otro, más contundente y activo con instituciones judiciales y represivas (Tribunales de Justicia en sede penal y agraria, y Fuerza Pública). Contrario a lo observado en San Bernardino, El Bambuzal contó con una fuerte presencia estatal, el adversario no se visualizaba directamente en la corporación del banano, sino en la estatalidad. La historia de este caso se escribe al compás de 4 desalojos.

Las y los campesinos tomaron posesión de las fincas el 22 de mayo del 2001, la entrada a la finca durante esos dos meses se basó en la táctica de iniciar la ocupación a orillas del terreno, cerca de la vía pública (Monestel, 2005), como una forma de hacer evidente y visible su presencia, así como de iniciar la adquisición paulatina de las tierras. El primer desalojo se lleva a cabo el 19 de julio del mismo año (Monestel, 2005) donde muere el campesino Randall Muñoz. Sin embargo, la organización campesina decide resistir y reingresar a la finca, al mismo tiempo que diversificaba sus tácticas, activando las vías institucionales para buscar una intervención estatal a su favor: petición de declaratoria de conflicto agrario en el IDA e iniciación de un juicio contra la SFC en el Juzgado Agrario de Guápiles.

En agosto del 2002 ocurrió el intento de un segundo desalojo, el cual fue interrumpido por una orden judicial del Juez Agrario de Guápiles. En julio del 2003 se ordenó el desalojo más violento en la historia de la ocupación, después de que la SFC demandara en sede penal a las y los campesinos por el delito de usurpación. La SFC no sólo retrae su intervención directa para ceder espacio a la mediación estatal institucional, lo hace en el tanto puede maniobrar con la ya dada por sentada titularidad sobre la tierra reconocida por el IDA y por el juzgado penal. La relación de fuerzas le favoreció enormemente pues tuvo la posibilidad real de canalizar sus objetivos por medio de la institucionalidad, sobre todo desde este escenario donde era la parte "ofendida".

Entre 2004 y 2005 aumentaron las denuncias por usurpación (rural como urbana, por tierra como por vivienda respectivamente). De acuerdo con Alejandro Chang, jefe del Departamento de Desalojos del Ministerio de Seguridad Pública, el promedio de desalojos de los años anteriores rondaba los 15 por 
año, para los primeros cinco meses del 2005 se habían ejecutado más de 30, y entre 2002 y 2003, 124 personas habían sido condenadas por usurpación (Vargas, 12 junio 2005), haciendo evidente la judicialización del tratamiento de los conflictos en torno a la propiedad privada.

El IDA denegó la declaratoria de conflicto agrario, eliminando el chance de una intervención administrativa, para dejarla en manos de los juzgados. Las posibilidades de entablar una relación de comunicación con las instituciones del estado se complejizaron, pues no solamente se hacía necesario seguir sus reglas y su lenguaje, sino también un conocimiento técnico y profesional que obligó a un nivel mayor de especialización de los miembros de la organización campesina. Se requería de un abogado con experiencia en el ramo, que sirviera como traductor del dialecto legal pero también como un representante legítimo, que cumpliera con los requisitos establecidos para tal efecto como, por ejemplo, tener una licencia profesional. Esas formas de hacer y decir son hegemónicas en el tanto condicionan el tipo de canales de comunicación, no como un consenso, sino más bien como una lucha, pues no se trata de "una ideología compartida sino un marco material y cultural común para vivir en, hablar de y actuar sobre los órdenes sociales caracterizados por la dominación” (Roseberry, 2007, p. 127). A partir de ese marco el grupo campesino halla las formas para manifestar su descontento y resistencia ante la situación vivida, entonces,

El problema no es entenderse entre gente que habla, en sentido propio o figurado, "lenguas diferentes", como tampoco remediar "fallos del lenguaje" mediante la invención de lenguajes nuevos. Es saber si los sujetos que se hacen contar en la interlocución "son" o "no son", si hablan o hacen ruido. Es saber si hay razón para ver el objeto que ellos designan como el objeto visible del conflicto. Es saber si el lenguaje común en el cual exponen la distorsión es verdaderamente un lenguaje común (Rancière, 2010, p. 69).

Ante este estado de las cosas, cabría además preguntarse sobre las posibilidades reales de dicho lenguaje para poder poner en evidencia el problema de un grupo que ha dejado de interesar, no sólo discursiva sino también estructuralmente, al proyecto económico neoliberal. En otras palabras, si bien ese lenguaje y procedimientos permiten un marco para comunicar el descontento, eso no implica necesariamente la escucha o aceptación de las demandas expresadas por el grupo social que pretende hablar y lograr objetivos concretos. El lenguaje común no exime de la discusión de parte de las autoridades sobre si la situación debe considerarse como un problema legítimo o no, ya que "ante todo sometimiento de afirmaciones y peticiones de validez entre interlocutores constituidos, está el litigio sobre el objeto del litigio, el litigio acerca de la existencia del litigio" (Rancière, 2010, p. 75).

En la experiencia específica de este conflicto agrario, la violencia estructural también se manifestó de manera física y directa, con consecuencias para la estabilidad, fuerza y motivación del grupo organizado. Se ejecuta un desalojo más, el cual es dictado aun estando vigente las medidas cautelares de protección, las que se anulan tres días después de la emisión de la orden de desalojo el 30 de junio de 2003, que es finalmente ejecutado el 10 de julio del 2003, con más de seiscientos efectivos de la Fuerza Pública y con presencia de todos los cuerpos especiales -antimotines, unidades antiterroristas, antidrogas, migración, unidades caninas, seguridad nacional, Organismo de Investigación Judicial (OIJ), así como de la seguridad privada de la SFC (Monestel, 2005). En la experiencia de la Señora I:

Ese desalojo fue peor. Fue tan salvaje animalada. Hubo un compañero muerto porque tiraron las bombas esas y él estaba lavándose, agachado, lavándose la cara y le dispararon por detrás (...) Vea ahí maltrataron niños, mujeres, embarazadas, enfermos, de todo. Y ahí no es eso que la policía atiende a la mujer, y el policía al hombre, ahí era garrote parejo, no les importaba nada (...) Nos metían la maquinaria y nos mataban todo lo que teníamos sembrado y nos botaban los ranchos y bueno. Pero igual nosotros, este, no tenemos a Bambuzal ni por falta de valor ni por miedo, no tenemos a Bambuzal por la corrupción (Anónimo, octubre 21, 2014).

La utilización de la negociación, la vía de derecho con pequeños, efímeros y finalmente falsos logros, ahora venía seguida de los fracasos. La relación con las instituciones del estado ahora estaba teñida de la represión violenta, el papel de instituciones como la Defensoría de los Habitantes de la 
República era meramente marginal, la defensa de garantías estaba limitada solamente a velar por la integridad física y ocurría de manera reactiva después de las intervenciones violentas de los cuerpos de seguridad pública y privada.

Minutos antes de la ejecución del desalojo, una parte de los campesinos había ofrecido resistencia, bloqueando la entrada pública a la finca e incluso armándose con armas hechizas de botellas y palos, así como machetes. Sin embargo, la fuerza de los policías fue mayor y lograron destruir los ranchos, así como los cultivos y animales de granja pertenecientes a las familias campesinas (DHR, 2004). El campesino Gerardo Moya muere de cinco balazos mientras se mantenían focos de resistencia campesina al desalojo que duraron unos nueve o diez días después de iniciado el mismo (Monestel, 2005). En palabras de la Señora I "ese desalojo fue, ese desalojo, no fue sólo un desalojo físico, digamos de unas tierras, fue un desalojo moral, internamente uno se siente, digamos un desalojo de los sueños, un desalojo de una vida mejor" (Anónimo, Octubre 21, 2014).

El desalojo ocurrido en abril del 2004 contó con grandes contingentes de Fuerza Pública y fue ejecutado por la Fiscalía sin orden judicial; de la misma manera, sin una orden, se encarcela a casi ochenta personas, a las que se les dicta prisión preventiva (Monestel, 2005). Dicha situación de violencia, seguida por otros desalojos, persecución y enfrentamientos lleva al grupo a movilizarse hacia San José. De nuevo toma un papel la idea de la centralidad territorial y política del estado, generando desplazamientos en el espacio, que como en el caso de San Bernardino terminan en la Catedral Metropolitana. La iglesia católica asume el rol de mediadora en las negociaciones de conciliación que se buscaron con la SFC a mediados del 2004. Después de 4 meses de vivir en la catedral, el grupo vuelve sin logros a Sarapiquí, donde ven vedado su ingreso a las tierras de El Bambuzal por medidas impuestas por la SFC en los juzgados y por grandes contingentes de la Fuerza Pública, lo que los obliga a refugiarse en unas tierras cercanas.

Al regreso se hizo evidente que la compañía bananera ponía en marcha tácticas para reapropiarse de las tierras. Se reforestó el terreno para darle otros usos en cultivos experimentales de exportación como plátanos y yuca orgánicos. Las modificaciones al terreno disputado impresionaron al grupo campesino, pues mostraban la determinación de la empresa bananera a eliminar su presencia de ahí. Mientras tanto, continuaron las acciones legales desde ambos bandos; sin embargo, los Juzgados penales y agrarios solo daban resoluciones que favorecían a la bananera. Cada uno de estos fracasos impactaba en la reducción del número de campesinos que permanecían en la organización. Por esta razón la organización se vuelve a movilizar a San José, a ocupar el vestíbulo de los Tribunales de Goicoechea, protesta que fue fuertemente reprimida. Luego de este evento se dio el juicio final por el caso de usurpación en perjuicio de la SFC donde las y los diecisiete campesinos acusados fueron condenados con libertad condicional (Vizcaíno, 29 setiembre 2005).

En este segundo episodio el abanico de intervención fue realmente amplio, el papel de las instituciones no logró responder a la demanda de tierra de los campesinos, ni tampoco al aseguramiento de garantías mínimas, como la seguridad o el trato igualitario; y más bien el uso de la fuerza fue desproporcionado. Derrotas como la de El Bambuzal significan la condensación de un proyecto productivo impuesto a nivel nacional visible en el funcionamiento que tienen las instituciones y las empresas, a través de una serie de mecanismos que frenan las posibilidades para la recuperación de tierras como ocurría en décadas anteriores.

\section{Conclusiones}

En este proceso de explotación y dominación se relacionan distintas escalas espaciales y temporales. La crisis financiera de la casa matriz transnacional Standard Fruit Company (Dole) a mediados de los años ochenta influyó en la venta de tierras de manera directa a los campesinos en San Bernardino, quienes daban una lucha local por la tierra. El abandono estatal de las instituciones técnicas especializadas en atender este tipo de situaciones no minó la voluntad del grupo que organizadamente logró 
mantener en el tiempo la ocupación, al punto de detener las amenazas de los guardas de la empresa y lograr una respuesta afirmativa de la SFC.

Dicho abandono empezaba a dar cuenta de lo que significaba el problema agrario en términos institucionales y por dónde caminarían las reformas que se gestaban con el ajuste estructural. Éste también desafiaba las ideas con la que usualmente se piensa al estado costarricense: fuerte, omnipresente y benefactor; al mismo tiempo, demuestra como "el estado" es intermitente en sus apariciones, además, se le encuentra donde menos se le busca, en la cotidianidad, en los lenguajes y prácticas que estructuran la resistencia sociopolítica de grupos organizados.

En ambos episodios encontramos una serie de relaciones selectivas entre instituciones del estado, el enclave y el campesinado. En el primer episodio, en el que se implementan las reformas de ajuste estructural, es correspondiente con un momento histórico en el que el discurso político hegemónico fue el de la contracción institucional. En el segundo episodio, estas reformas se suponen sedimentadas, y la contracción estatal efectuada, sin embargo y paradójicamente, en este periodo la ausencia y la reducción de los ámbitos de acción no fueron la tónica, como en el caso de San Bernardino, pues se dieron formas concretas de acción institucional: en ámbitos como la seguridad y represión la presencia fue intensa, mientras que, respecto a garantías y derechos humanos, y en lo técnico-agrario, el papel estatal fue superficial. A pesar del discurso de retracción, el nivel de intervención confirma no solo la judicialización de los problemas sociales, sino también la criminalización de los liderazgos campesinos.

Contrario al ideario benefactor que caracteriza la historiografía estatal en Costa Rica, el caso en el que la ausencia institucional del estado (mas no así ausencia cultural ni subjetiva) fue el caso de éxito en términos de acceso a la tierra por parte de las y los campesinos en ocupación, mientras que el caso que resultó fallido contó con el más variado abanico de intervención.

\section{Referencias}

Abrams, Philip. (1988). "Notes on the Difficulty of Studying the State (1977)". Journal of Historical Sociology. 1, 1: 58-89.

Bernstein, Henry. (2010). Class Dynamics of Agrarian Change. Nova Scotia: Fernwood Publishing / Kumarian Press.

Boix, Vicente. (2005). "Un artefacto químico que sigue estallando". Voltaire Net, 1 de Diciembre: Recuperado de http://www.voltairenet.org/article131905.html

Bucheli, Marcelo. (2006). Good Dictator, Bad Dictator: United Fruit Company and Economic Nationalism in Central America in the Twentieth Century. Working Paper. Illinois: University of Illinois at Urbana-Champaign, College of Business.

Cartín, Sandra, \& Román, Isabel. (1991). Echando raíces. La lucha por la tierra en Costa Rica. Documento de análisis 17. San José: Centro de Estudios para la Acción Social.

Edelman, Marc (2005). Campesinos contra la globalización. Movimientos sociales rurales en Costa Rica. San José: Editorial de la Universidad de Costa Rica.

Gluckman, Max (1968). The Utility of the Equilibrium Model in the Study of Social Change. American Anthropologist Vol. 70, $N^{\circ} 2$, 219-237.

Guillén Araya, María José. (2015). Estado, enclave y campesinado. Conflicto agrario en Río Frío de Sarapiquí, 1980-2009 (Tesis de Licenciatura en Ciencias Políticas). Universidad de Costa Rica, Costa Rica.

Hough, Phillip. (2012). "A race to the bottom? Globalization, Labor Repression, and Development by Dispossesion in Latin America's Banana Industry". Global Labor Journal, 2, 3: 236-263.

Kautsky, Karl. (2015). La cuestión agraria. Estudio de las tendencias de la agricultura moderna y de la política agraria de la socialdemocracia. Barcelona. Recuperado de https://www.marxists.org/ espanol/kautsky/1899/kautsky-la-cuestion-agraria.pdf 
Lenin, Vladimir Ilich. (1972). El desarrollo del capitalismo en Rusia. Santiago: Empresa Editora Nacional Quimantu.

León, Andrés. (2008). Acumulación y Regulación en la Región Huetar Norte (1985-2005): Destrucción creativa y articulación transnacional (Tesis de Maestría en Ciencias Políticas). Universidad de Costa Rica, Costa Rica.

León, Jorge. (2012). Historia Económica de Costa Rica en el Siglo XX. Tomo II: La Economía Rural. San José: Instituto de Investigaciones en Ciencias Económicas y Centro de investigaciones Históricas de América Central de la Universidad de Costa Rica.

Mitchell, Timothy. (1991). "The Limits of the State: Beyond Statist Approaches and Their Critics." American Political Science Review 85: 77-96.

Ollman, Bertell (2003). Dance of the Dialectic. Steps in Marx's Method. Urbana and Chicago: University of Illinois Press.

Rancière, Jaques. (2010). El desacuerdo. Política y filosofía. Buenos Aires: Ediciones Nueva Visión.

Rodríguez, Carlos. (1998). "Region Huetar Norte. Transformación productiva y desafíos regionales". Ponencia preparada para el Cuarto Informe sobre el Estado de la Nación en Desarrollo Humano Sostenible, Costa Rica.

Román, Isabel. (1994). ¿Conciliación o Conflicto? Luchas campesinas y democracia en Costa Rica. San José: Editorial Porvenir.l

Román, Isabel, \& Peraza, Damaris. (1990) La Lucha por la Tierra en el Cantón de Sarapiquí, 19601985. Un análisis dinámico (Tesis de Licenciatura en Sociología). Universidad de Costa Rica, Costa Rica.

Roseberry, William. (2007). Hegemonía y el Lenguaje de la Controversia. En M. Lagos y P. Calla (eds.) Antropología del Estado. Dominación y prácticas contestatarias en América Latina (pp. 117137). La Paz, Bolivia: INDH/PNUD.

Scott, James. (1998). Seeing like a state. How certain schemes to improve human condition have failed. New Haven and London: Yale University Press.

Vargas, Otto. (12 junio 2005). "Precaristas invaden un terreno cada cuatro días”. La Nación, 12 de junio. Recuperado de http://wvw.nacion.com/ln_ee/2005/junio/12/pais0.html

Vizcaíno, Irene. (29 setiembre 2005). "Campesinos condenados por usurpar la finca Bambuzal”. La Nación, 29 de setiembre. Recuperado de http://wvw.nacion.com/ln_ee/2005/septiembre/29/sucesos1.html

\section{Referencias de fuentes primarias}

Anónimo. (Setiembre 16, 2014). Entrevista.

Anónimo. (Octubre 21, 2014). Entrevista.

Defensoría de los Habitantes de la República (2001). Informe final con recomendaciones Oficio $\mathrm{N}^{\circ}$ 06441-2001-DHR (Expediente N¹1263-22-2001-QJ)”. San José.

Defensoría de los Habitantes de la República (2004). Ampliación del Informe de Cierre de Expediente en Seguimiento Oficio Nº0474-2004-DHR (Expediente N 11263-22-2001-QJ)". San José.

Instituto de Desarrollo Rural (1999-2003). Expediente 3102 El Maná. San José: Folios. 296-295. San José.

Instituto de Desarrollo Rural (2014). Lista de fincas (Región Heredia, Subregión La Virgen). San José. Monestel, Héctor. (2005). Conflicto Agrario de Bambuzal. Reseña Cronológica. San José. Documento personal no publicado. 